\title{
Tercer Consenso Nacional de Acromegalia: recomendaciones para su diagnóstico, tratamiento y seguimiento
}

\section{Third National Consensus on Acromegaly: Recommendations for diagnosis, treatment, and follow-up}

\author{
Coralys Abreu-Rosario ${ }^{1}$, Diego Cadena-Obando², Alma Vergara-López ${ }^{1}$, Ana l. Espinosa de los Monteros-SáncheZ ${ }^{3}$, \\ Lesly Portocarrero-Ortiz ${ }^{4}$, Pedro Gómez-Romero5 ${ }^{5}$, M. Citlalli Pérez-Guzmán ${ }^{1}$, Daniel Cuevas-Ramos 6 , \\ Alfredo A. Reza-Albarrán ${ }^{6}$, Baldomero González-Virla 3 , Ernesto Sosa-Erosa ${ }^{3}$, Gabriela Rangel-Sánchez ${ }^{7}$, \\ Adriana Balderrama-Soto ${ }^{1}$, Maricela Vidrio-VelázQuez ${ }^{8}$, Carolina Pérez-Castañeda², Aleida Rivera-Hernández ${ }^{9}$, \\ FAysi Fernández-OjedA ${ }^{10}$, Graciela Gómez-Martínez ${ }^{11}$, EduARdo BreA-Andrés ${ }^{12}$, Araceli Eulogia-Perña URAGA ${ }^{13}$,

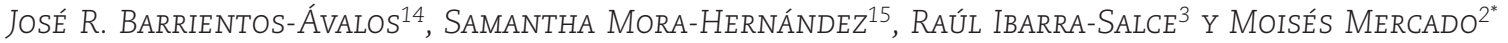

${ }^{1}$ Servicio de Endocrinología, Centro Médico Nacional 20 de Noviembre, Instituto de Seguridad y Servicios Sociales de los Trabajadores del Estado, Ciudad de México; ${ }^{2}$ Unidad de Investigación Médica de Enfermedades Endocrinas, Hospital de Especialidades, Centro Médico Nacional Siglo XXI, Instituto Mexicano del Seguro Social, Ciudad de México; ${ }^{3}$ Servicio de Endocrinología, Hospital de Especialidades, Centro Médico Nacional Siglo XXI, Instituto Mexicano del Seguro Social, Ciudad de México; ${ }^{4}$ Servicio de Endocrinología, Instituto Nacional de Neurología y Neurocirugía Manuel Velasco Suárez, Ciudad de México; ${ }^{5}$ Departamento de Medicina, Hospital Ángeles Pedregal, Ciudad de México; ${ }^{6}$ Servicio de Endocrinología, Instituto Nacional de Ciencias Médicas y Nutrición Salvador Zubirán, Ciudad de México; ${ }^{7}$ Hospital de Especialidades, Centro Médico de Occidente, Instituto Mexicano del Seguro Social, Guadalajara, Jal.; ${ }^{8}$ Expresidencia, Sociedad Mexicana de Nutrición y Endocrinología, Ciudad de México; ${ }^{9} \mathrm{Hospital}$ de Pediatría, Centro Médico Nacional Siglo XXI, Instituto Mexicano del Seguro Social, Ciudad de México; ${ }^{10}$ Unidad Médica de Alta Especialidad N. ${ }^{\circ} 25$, Hospital de Alta Especialidad Ignacio García Téllez, Instituto Mexicano del Seguro Social, Mérida, Yuc.; ${ }^{11}$ Unidad Médica de Alta Especialidad N. ${ }^{\circ}$ 25, Centro Médico del Noreste, Instituto Mexicano del Seguro Social, Monterrey, N.L.; ${ }^{12}$ Centro Médico, Instituto de Seguridad Social del Estado de México y Municipios, Toluca, Edo. de México; ${ }^{13}$ Servicio de Endocrinología, Hospital Regional Gral. Ignacio Zaragoza, Instituto de Seguridad y Servicios Sociales de los Trabajadores del Estado, Ciudad de México; ${ }^{14}$ Servicio de Endocrinología, Hospital Civil de Guadalajara Fray Antonio Alcalde, Guadalajara, Jal.; ${ }^{15}$ Unidad Médica de Alta Especialidad N. ${ }^{14}$, Centro Médico Nacional Adolfo Ruiz Cortines, Instituto Mexicano del Seguro Social, Ver. México

\section{RESUMEN}

La acromegalia es una enfermedad crónica con manifestaciones multisistémicas. La evidencia actual continúa acrecentando nuestra comprensión sobre la historia natural de la enfermedad y sobre la respuesta a las herramientas terapéuticas disponibles. El objetivo del presente documento es actualizar la posición de la Sociedad Mexicana de Nutrición y Endocrinología respecto al diagnóstico, tratamiento y seguimiento de los

\begin{abstract}
Acromegaly is a chronic disease with multisystemic manifestations. Current evidence provides more robust knowledge about the natural history of the disease and therapeutic response. The objective of this document is to update the position of the Mexican Society of Nutrition and Endocrinology regarding the diagnosis, treatment, and follow-up of patients with acromegaly, based on a systematic review of
\end{abstract}

Correspondencia:

*Moisés Mercado

E-mail: mmercadoa@yahoo.com
Fecha de recepción: 02/12/2020

Fecha de aceptación: 04/02/2021

DOI: 10.24875/RME.M21000007
Disponible en internet: 20-03-2021

Rev Mex Endocrinol Metab Nutr. 2021;8:(SUPL. 1):3-21

2462-4144 / ๑ 2021 Sociedad Mexicana de Nutricion y Endocrinologia, AC. Publicado por Permanyer. Éste es un artículo open access bajo la licencia CC BY-NC-ND (http://creativecommons.org/licenses/by-nc-nd/4.0/). 
pacientes que viven con acromegalia, realizando una revisión de la literatura por parte del Grupo de Trabajo de Neuroendocrinología de nuestra Sociedad y estableciendo recomendaciones aplicables para nuestra población.

Palabras clave: Acromegalia. Diagnóstico. Tratamiento. Escrutinio.

\section{INTRODUCCIÓN}

La acromegalia es una patología crónica poco frecuente con manifestaciones sistémicas. Está causada por hipersecreción de la hormona de crecimiento $(\mathrm{GH})$ y, por lo tanto, del factor de crecimiento similar a la insulina tipo 1 (IGF-1). Su diagnóstico tardío, la complejidad que puede representar su manejo y las barreras económicas y sociales son algunos de los retos de este padecimiento, por lo que desde el momento de su diagnóstico los pacientes deben ser referidos a un tercer nivel de atención. Como antecedentes a este documento, en $2004^{1}$ y en $2007^{2}$ se publicaron sendos consensos de la Sociedad Mexicana de Nutrición y Endocrinología (SMNE) que han abordado el diagnóstico, tratamiento y seguimiento de esta enfermedad. En los últimos años se ha generado nueva evidencia sobre esta enfermedad y ha aumentado la comprensión de su fisiopatología e historia natural, motivo por el cual surgió la necesidad de actualizar el posicionamiento de nuestra Sociedad. Con dicho objetivo, se llevó a cabo una reunión con 23 expertos del Grupo de Trabajo de Neuroendocrinología de la SMNE, en la cual se presentaron los datos y las revisiones más actuales sobre el diagnóstico y el tratamiento de la acromegalia, se discutieron las recomendaciones apropiadas para la población mexicana y cuáles de estas son aplicables, tomando en cuenta las características propias de esta población. Se propusieron las directrices y algoritmos descritos a lo largo de este texto basados en los acuerdos de esta discusión.

\section{DIAGNÓSTICO BIOQUÍMICO DE ACROMEGALIA}

En pacientes con manifestaciones características de crecimiento acral o con múltiples enfermedades the literature conducted by the Neuroendocrinology Working Group of our Society, generating specific guidelines for our Mexican population.

Key words: Acromegaly. Diagnosis. Treatment. Screening.

asociadas a acromegalia se debe realizar un estudio bioquímico para establecer el diagnóstico de dicha enfermedad (Fig. 1). Existe una gran cantidad de ensayos disponibles comercialmente para la determinación de los niveles de GH e IGF-1, pero no todos cumplen con los criterios indispensables para aportar información confiable.

La determinación del IGF-1 es el mejor estudio de escrutinio de acromegalia debido a que solo es necesaria una muestra de sangre y a que sus niveles varían poco durante el día, reflejando las concentraciones integradas de $\mathrm{GH}$ en 24 horas. Sus niveles varían con la edad: alcanzan su nivel máximo durante la pubertad y posteriormente decaen conforme avanza la edad del paciente. Dichos niveles deben expresarse como número de veces por encima del límite superior del rango de normalidad (LSN) para edad, por lo que es necesario contar con valores normativos poblacionales obtenidos de por lo menos 700 personas sanas distribuidas entre los 18 y los 70 años. Si bien anteriormente también se ajustaban según el sexo, se ha observado que la variabilidad entre hombres $y$ mujeres es mínima ${ }^{3,4}$. Recomendamos una determinación 1.2 veces por arriba del LSN para la edad como criterio diagnóstico de acromegalia 5 .

El IGF-1 circulante se encuentra unido en más del $90 \%$ a proteínas transportadoras, de las cuales la más abundante es la proteína 3 de unión al IGF (IGFBP3). Es necesario pretratar la muestra para separar el IGF-1 de esta, ya que de otra forma se sobreestima su concentración. Existen varios métodos para separar el IGF-1 de sus proteínas de unión, de los cuales el más comúnmente utilizado es la precipitación con ácido-alcohol. En relación con la preparación estándar, se debe usar la IGF-1 recombinante humana $87 / 518$ o 02/254 y los valores deben ser presentados en unidades de masa $(\mathrm{ng} / \mathrm{ml}$ o $\mu \mathrm{g} / \mathrm{l})$. Los inmunoensayos deben usar anticuerpos monoclonales altamente específicos y sensibles ${ }^{3,6,7}$. 


\section{Algoritmo diagnóstico de acromegalia}

Sospecha clínica de acromegalia

Medir GH basal, GH posglucosa e índice IGF-1 (LSN)*

GH basal $<1$ Mg/l, IGF-1 $<1.2$ LSN y

GH posglucosa nadir $<0.4 \mu \mathrm{g} / \mathrm{l}$

\section{Descarta acromegalia}

*Usar los tres criterios basales en el diagnóstico. Índice IGF-] (IGF-1 basal/límite superior normal para edad y sexo).

TRM: resonancia magnética de hipófisis con y sin gadolinio en fase dinámica, cortes coronales y sagitales, en secuencias T1 y T2.

TC solo en casos de contraindicación de la RM.

Aspectos analíticos:

$\mathrm{GH}$ requisitos: ensayo ultrasensible monoclonal que use la preparación estándar WHO 2000-98/574. [GF-1 requisitos: inmunoensayo monocional previa extracción con ácido-alcohol y preparación estandar 02/254 o 87/518. Idealmente se debe contar con valores normales de referencia en cada población que incluya por lo menos 500 controles sanos, hombres y mujeres distribuidos entre los 18 y los 70 años. Si no se cuenta con lo anterior se usa el normograma del método analítico que se estéutilizando.

Existe controversia sobre el valor de $\mathrm{GH}$ nadirsi es menos de 10 menos de $0.4 \mu \mathrm{g} / \mathrm{l}$, nosotros consideramos el $0.4 \mu \mathrm{g} / \mathrm{l}$ en relación a las pruebas ultrasensibles.

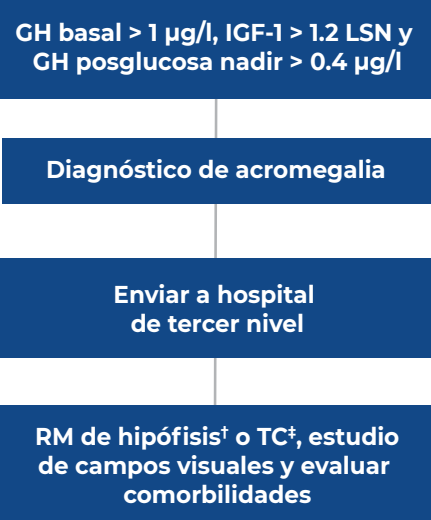

Figura 1. Diagnóstico bioquímico de acromegalia. IGF-1: factor de crecimiento similar a la insulina tipo 1; GH: hormona de crecimiento; RM: resonancia magnética; TC: tomografía computarizada; LSN: límite superior del rango de normalidad.

Si bien se ha descrito que los valores basales o al azar de GH no son de utilidad para el diagnóstico de acromegalia debido a su pulsatilidad ${ }^{8}$, este consenso considera importante la determinación de la GH basal al diagnóstico debido a que la evidencia actual indica que este valor es de relevancia pronóstica. Un valor de GH basal al diagnóstico > $10 \mu \mathrm{g} / \mathrm{l}$ se asocia a una mayor probabilidad de actividad de la enfermedad después del tratamiento quirúrgico inicial ${ }^{9}$. La determinación de la GH después de una carga de glucosa es el estudio dinámico diagnóstico más específico para la enfermedad y se debe realizar para corroborar el diagnóstico de acromegalia en pacientes con un IGF-1 elevado. Un valor mayor a $0.4 \mu \mathrm{g} / \mathrm{l}$ después de una carga de 75 gramos de glucosa es diagnóstico de acromegalia ${ }^{10,11}$, siempre y cuando se utilicen ensayos ultrasensibles y con las características que se mencionan más adelante. Si no se tiene la certeza de contar con una determinación GH con estas características, se recomienda usar un valor de corte de $1 \mu \mathrm{g} / /^{10,11}$. El ensayo de GH debe estar calibrado de acuerdo con la preparación estándar internacional de $\mathrm{GH}$ recombinante humana $98 / 574$, la cual consiste solamente de GH monomérica de $22 \mathrm{KDa}$. Por definición, $1 \mathrm{mg}$ de esta preparación equivale a $3 \mathrm{Ul}$; los resultados deben ser expresados en unidades de masa $(\mathrm{ng} / \mathrm{ml}$ o $\mu \mathrm{g} / \mathrm{l})$ y el inmunoensayo debe usar anticuerpos altamente afines y específicos, usualmente de origen monoclonal, que identifiquen solamente la GH de $22 \mathrm{KDa}$ y que no crucen con otras isoformas de la $\mathrm{GH}$ como la de $20 \mathrm{KDa}^{12,13}$.

\section{DIAGNÓSTICO PATOLÓGICO E INMUNOHISTOQUÍMICO}

Los estudios de histología, inmunohistoquímica (IHQ) y microscopia electrónica han dado evidencia sólida y consistente de que existe una gran diversidad de tumores del somatotropo productores de $\mathrm{GH}$. La hiperplasia del somatotropo sin adenoma puede encontrarse en los raros casos de secreción ectópica de hormona liberadora de $\mathrm{GH}$, usualmente por neoplasias neuroendocrinas localizadas en timo, bronquios o páncreas endocrino y en algunos casos de acromegalia familiar ${ }^{14-16}$. 
Tabla 1. Marcadores clínicos y de inmunohistoquímica para realizar la adecuada clasificación de adenomas del somatotropo

\begin{tabular}{llll}
\hline Marcador & Tipo 1 & Tipo 2 & Tipo 3 \\
\hline Tamaño & Microadenomas & Macroadenomas & Macroadenomas \\
\hline Invasión & Ausente o presente & Ausente & Presente \\
\hline Granulación (Cam 5.2) & Densa & Densa o escasa & Escasa \\
\hline Ki67\% & $<3 \%$ & $3 \%$ & $>3 \%$ \\
\hline p21 & Alto & Intermedio & Bajo \\
\hline Receptor tipo 2 de somatostatina & Alto & Intermedio & Bajo \\
\hline Respuesta a ligandos del receptor de somatostatina & Mejor & Intermedia & Mala \\
\hline Pronóstico & Mejor & Intermedio & Malo \\
\hline
\end{tabular}

\section{Tinciones convencionales}

Es necesario realizar tinciones convencionales en todo adenoma del somatotropo: hematoxilina y eosina para determinar si la celularidad es acidófila, basófila o cromófoba; la tinción con ácido peryódico de Schiff para evaluar el citoplasma y la reticulina y tinción de plata para diferenciar entre hipófisis sana, adenoma o hiperplasia. Posteriormente se debe realizar una evaluación de IHQ para prolactina (PRL), $\mathrm{GH}$, gonadotropinas, tirotropina y corticotropina. La subunidad alfa puede ser un marcador necesario en casos poco frecuentes de acromegalia, como son los tumores con secreción mixta.

\section{Marcadores útiles de inmunohistoquímica}

Por la diversidad de presentaciones clínicas de la acromegalia es recomendable evaluar detalladamente a cada paciente para determinar su pronóstico. Actualmente es recomendable establecer si se trata de un microadenoma o un macroadenoma, valorar la presencia de invasión a senos cavernosos y determinar los marcadores de pronóstico por IHQ como el patrón de granulación, el índice proliferativo Ki67 y la expresión de p21. El patrón de granulación se establece mediante la inmunotinción con anticuerpos frente a citoqueratinas CAM5.2, en la cual los adenomas densamente granulados aparecen con positividad difusa en el citoplasma, mientras que los escasamente granulados muestran los llamados cuerpos fibrosos en los que la inmunorreactividad se concentra en el núcleo. Aunque no está universalmente aceptado, la inmunotinción con anticuerpos frente al receptor somatostatinérgico tipo 2 (SSTR2) puede ser de utilidad en predecir la respuesta a análogos de la somatostatina de primera generación ${ }^{17-19}$. Los pacientes con acromegalia tienen distinto pronóstico de acuerdo con los marcadores clínicos, de imagen e IHQ (Tabla 1) ${ }^{19}$.

\section{Marcadores en casos especiales}

Algunos marcadores de IHQ pueden ser útiles en situaciones especiales o en casos con algún patrón de herencia específico, como se enlista a continuación ${ }^{14-16}$.

- La proteína de interacción con hidrocarburos arilados en casos de tumores hipofisarios hereditarios aislados, generalmente productores de $\mathrm{GH}$ y en menor medida PRL y hormona adrenocorticotrópica, que ocurren en pacientes jóvenes (es una causa de gigantismo); con frecuencia son macroadenomas invasivos y responden pobremente a análogos de la somatostatina de primera generación. Esta proteína puede ser detectada por IHQ utilizando anticuerpos específicos.

- La metil-guanidil-metil-transferasa es una enzima que metaboliza a la temozolomida, que es un agente alquilante usado en los casos extremadamente raros de carcinomas hipofisarios. Evaluada por IHQ, una pobre inmunotinción se relaciona con una mejor respuesta.

- El factor de crecimiento vascular endotelial para proliferación y angiogénesis.

- La e-cadherina ha sido informada como marcador de mayor invasión. 
- El factor de transcripción Pit-1 o POU1F1 es relevante para fines de investigación, pero no en la práctica clínica diaria, pues no discrimina ni el tipo ni el pronóstico de los pacientes con acromegalia.

- El marcador p53 no se considera como marcador de utilidad en acromegalia.

\section{HIPERTENSIÓN Y CARDIOPATÍA EN ACROMEGALIA}

La hipertensión arterial (HA) y la enfermedad cardiovascular (ECV) están entre las comorbilidades más frecuentes de la acromegalia. La ECV contribuye con una mortalidad de hasta el $60 \%{ }^{20,21}$, aunque también se ha informado en los últimos años que las causas de mortalidad en la acromegalia se han desviado de la ECV a las neoplasias malignas ${ }^{22}$. La presencia de ECV en el momento del diagnóstico presagia una mortalidad casi del $100 \%$ a 15 años $^{20}$.

\section{Hipertensión arterial}

La prevalencia de la HA varía del 20 al $50 \%{ }^{23}$, informándose en México una prevalencia del $27 \%$ en pacientes con acromegalia ${ }^{24}$. Las variaciones en la prevalencia se deben a las diferencias que hay en la definición de HA, las técnicas de medición, el sexo, la edad, el grupo étnico, la edad en la que se diagnosticó la acromegalia y la presencia de otras alteraciones hipofisarias y de otras enfermedades como diabetes mellitus ${ }^{25}$. La HA no es más frecuente en un sexo; predomina la presencia de hipertensión diastólica y está menos frecuentemente relacionada con la historia familiar. En estudios de monitoreo de la presión arterial (PA) por 24 horas se observa una prevalencia de casi un 50\% de non dippers, es decir, de pacientes en quienes no disminuye la PA en la noche durante el sueño ${ }^{20,26}$.

Entre los factores relacionados con el origen de la HA en la acromegalia están: la duración de la enfermedad, las concentraciones de GH e IGF-1, el índice de masa corporal, la edad, la presencia de resistencia a la insulina o de apnea obstructiva del sueño, la disfunción endotelial y el aumento del estrés cardiaco por aumento en la precarga y la poscarga. En un estudio de Schutte, et al. se mostró una relación directa entre los niveles de IGF-1 y el riesgo de $\mathrm{HA}^{27}$. El exceso de GH e IGF-1 favorecen la expansión de volumen, una mayor estimulación de las células del músculo liso vascular, aumento en la rigidez arterial, alteración en la función endotelial y un aumento de la respuesta a la angiotensina II. A nivel renal se ha documentado un incremento en la retención de sodio y agua. Todo esto trae como consecuencia un aumento en el gasto cardiaco y en las resistencias periféricas que culminan en el desarrollo de $\mathrm{HA}^{28}$. Kamenicky, et al. documentaron en modelos animales que la GH aumenta la expresión del gen de la subunidad $\alpha$ del canal epitelial de sodio (ENaC) y de la cinasa 1 regulada por glucocorticoides y suero, que regula la expresión y estabilidad del $\mathrm{ENaC}^{29}$. La resistencia a la insulina, que forma parte de las anormalidades metabólicas de la acromegalia, contribuye al desarrollo de la HA. La hiperinsulinemia compensadora aumenta la reabsorción de sodio en el asa de Henle, lo que disminuye la cantidad de sodio que llega a la mácula densa en el túbulo contorneado distal, por lo que se activa el sistema renina-angiotensina-aldosterona, aumentando la reabsorción de sodio, con la consecuente expansión del volumen sanguíneo ${ }^{20,25}$.

\section{Enfermedades cardiovasculares}

Las complicaciones cardiovasculares (CV) de la acromegalia incluyen: hipertrofia de ventrículo izquierdo o biventricular, aumento del septum interventricular, disfunción diastólica en reposo y/o disfunción sistólica de esfuerzo, insuficiencia cardiaca, arritmias y valvulopatía, acompañadas de disfunción endotelial y aumento del grosor de la íntima-media carotídea. Se pueden describir tres etapas de la disfunción $\mathrm{CV}^{20,30}$ :

- Primera fase o temprana: presencia de hipertrofia de ventrículo izquierdo/biventricular, con elevación de la frecuencia y del gasto cardiaco; es un síndrome hipercinético.

- Segunda fase: disfunción diastólica y disfunción sistólica; en pacientes de larga evolución el 90\% tienen hipertrofia cardiaca. 
- Fase final de la enfermedad no tratada o no controlada: cardiomiopatía dilatada/insuficiencia cardiaca. En esta etapa el daño es irreversible.

En una revisión de 17 series de pacientes con acromegalia, la prevalencia de la hipertrofia del ventrículo izquierdo varía del 11 al 78\% y la de la disfunción diastólica del ventrículo izquierdo del 11 al $75 \%{ }^{31}$. La disfunción sistólica se reporta con menos frecuencia, con una prevalencia del 1.6 al $26.3 \%^{31}$.

La mayoría de las series evalúan los diferentes componentes de la ECV con ultrasonido ${ }^{32}$. En años recientes se ha empleado la resonancia magnética nuclear cardiaca (RMC); en estos estudios se informa una menor prevalencia de hipertrofia de ventrículo izquierdo y de fibrosis miocárdica, lo que hace suponer que los estudios ecocardiográficos sobreestiman su frecuencia. Gadelha, et al. informaron que solo un 13.5\% de los pacientes presentaron hipertrofia de ventrículo izquierdo por RMC, frente a un 31\% por ecocardiografía ${ }^{31}$. La cardiopatía isquémica no parece ser más prevalente entre los pacientes con acromegalia que en la población general. Un estudio alemán informó una incidencia estandarizada de 0.89 (0.47 a 1.52). También se ha documentado un calcio coronario más bajo en estos pacientes ${ }^{31,33}$.

Colao, et al. informaron en el 2003 que un $75 \%$ de los pacientes presentan alteraciones valvulares al momento del diagnóstico. Esta cifra varía dependiendo de la serie que se revise, lo mismo que el grado de insuficiencia valvular. La valvulopatía mitral es la más frecuente, seguida de la aórtica. Estas alteraciones son más frecuentes en los pacientes con enfermedad activa que en los controlados o en remisión $^{34}$. Gadelha, et al. informaron un incremento anual del $19 \%$ de enfermedad valvular en pacientes activos $^{30}$. El mecanismo fisiopatogénico involucrado es una alteración en la regulación de la matriz extracelular con depósito de colágeno y mucopolisacáridos a nivel de las valvas, lo que condiciona fragilidad valvular e insuficiencia ${ }^{31}$. La detección de ectasia aórtica con un diámetro de la raíz de la aorta $\geq 3.8 \mathrm{~cm}$ se relaciona con el desarrollo de insuficiencia aórtica o de disección de sus paredes ${ }^{35,36}$.

Las arritmias que se han informado en pacientes con acromegalia en estudios Holter son ectopia ventricular aislada o en pares en el 71 y $21 \%$
Tabla 2. Pruebas diagnósticas empleadas para identificar las comorbilidades cardiovasculares de los pacientes con acromegalia

- Toma de PA en cada consulta

- Monitoreo ambulatorio de la PA (por el paciente en casa)

- Tele de tórax y electrocardiograma

- Monitoreo continuo de la PA (24 horas)

- Ecocardiograma

- Ecocardiograma Doppler tisular

- EKG (si hay anormalidades en la exploración física)

- Holter si se detectan alteraciones del ritmo

- Prueba de esfuerzo

- Tomografía coronaria

- Gammagrama cardiaco

- RMC

EKG: electrocardiograma; PA: presión arterial; RMC: resonancia magnética cardiaca. Adaptada de Ramos-Leví, et al., $2019^{28}$.

respectivamente, la ectopia supraventricular aislada o en pares en el 89 y $39 \%$, la taquicardia ventricular no sostenida en el $11 \%$ de los casos y la taquicardia supraventricular no sostenida en el $46 \%$. Estas alteraciones son consecuencia de la fibrosis intersticial, alteraciones miofibrilares e hipertrofia cardiaca. En pacientes con acromegalia se ha descrito la disincronía del ventrículo izquierdo por pérdida del pico simultáneo en la contracción de los diferentes segmentos $\operatorname{cardiacos}^{30,37}$.

Se ha descrito una prevalencia de enfermedad cerebrovascular del 1.2 al $7.1 \%^{38}$; sin embargo, son pocas las series que la informan. Schöfl, et al. calculan una incidencia estandarizada igual que la de la población general (1.17 [0.66-1.93]; $p=0.61)$. En pacientes con HA la incidencia es mayor, 94 vs. $43 \%$ en pacientes sin HA ( $p<0.001)$. Por el contrario, cuando la acromegalia ha sido tratada con radioterapia (RT), la mortalidad estandarizada por enfermedad cerebrovascular es alta, de 4.42 (rango: 1.71-7.22) ${ }^{39}$. Su fisiopatogenia se debe a los niveles elevados de GH e IGF-1. En modelos animales se ha identificado expresión de receptores de $\mathrm{GH}$ en miocardio y vasos sanguíneos. El IGF-1 induce hipertrofia celular miocárdica e induce expresión de cadenas ligeras de miosina, troponina I y actina a muscular cardiaca. En humanos, el IGF-1 tiene efecto inotrópico positivo, aumenta el calcio intracelular porque aumenta la corriente de calcio en los canales de calcio tipo $\mathrm{L}$ y el intercambio $\mathrm{Na}^{+} / \mathrm{H}^{+28}$. 
Tabla 3. Ventajas y desventajas de los estudios diagnósticos para identificar las comorbilidades cardiovasculares de los pacientes con acromegalia

\begin{tabular}{|c|c|c|}
\hline & Ventaja & Desventaja \\
\hline $\begin{array}{l}\text { Medición ordinaria de PA } \\
\text { en consulta }\end{array}$ & Simple, no invasiva, corta duración & Puede sobreestimar la prevalencia de la HA \\
\hline$\overline{E K G}$ & $\begin{array}{l}\text { Identifica a pacientes con más riego } \\
\text { de trastornos del ritmo }\end{array}$ & Valor pronóstico \\
\hline Ecocardiograma & $\begin{array}{l}\text { No invasivo, alta resolución de la anatomía } \\
\text { y función. Útil para evaluar la severidad y } \\
\text { extensión de la cardiomiopatía. Costo moderado. } \\
\text { Buena reproducibilidad }\end{array}$ & $\begin{array}{l}\text { La masa del VI puede ser sobreestimada o } \\
\text { subestimada por la fórmula, que puede amplificar } \\
\text { errores }\end{array}$ \\
\hline $\begin{array}{l}\text { Ecocardiograma Doppler } \\
\text { tisular }\end{array}$ & $\begin{array}{l}\text { En etapas tempranas identifica alteración } \\
\text { biventricular de la función sistólica }\end{array}$ & Las mismas \\
\hline Gammagrama cardiaco & $\begin{array}{l}\text { Evaluación no invasiva del llenado diastólico } \\
\text { rápido. Evalúa la integridad del rendimiento } \\
\text { cardiaco }\end{array}$ & $\begin{array}{l}\text { Requiere administración endovenosa del } \\
\text { radiofármaco } \\
\text { Costoso }\end{array}$ \\
\hline RMC con gadolinio & $\begin{array}{l}\text { Estándar de oro. Mayor precisión y } \\
\text { reproducibilidad con menor variabilidad que } \\
\text { con el EKG. Se evalúa el tiempo de relajación } \\
\text { miocárdica; forma no invasiva de detectar } \\
\text { edema miocárdico y de esta manera las acciones } \\
\text { directas de la GH y el IGF-1 en corazón. } \\
\text { Sirve para evaluar el efecto del tratamiento }\end{array}$ & $\begin{array}{l}\text { Menos disponible } \\
\text { Mayor costo } \\
\text { Inconsistencia costo/efectividad }\end{array}$ \\
\hline
\end{tabular}

EKG: electrocardiograma; HA: hipertensión arterial; PA: presión arterial; VI: ventrículo izquierdo; GH: hormona de crecimiento; IGF-1: factor de crecimiento similar a la insulina tipo 1; RMC: resonancia magnética cardiaca.

Adaptada de Ramos-Leví, et al., $2019^{28}$.

En la tabla 2 se resumen las pruebas diagnósticas que pueden ser usadas para identificar las diferentes alteraciones $\mathrm{CV}$ en los pacientes con acromega$\mathrm{lia}^{28}$. En la tabla 3 se describen las ventajas y las desventajas de cada una de las pruebas recomendadas en el escrutinio y evaluación de las comorbilidades CV.

\section{EFECTOS DEL TRATAMIENTO EN LAS COMORBILIDADES CARDIOVASCULARES}

El control del exceso de GH e IGF-1 mejora la estructura y la función cardiacas, el daño vascular; el control de la HA, la hipertrofia cardiaca, la disfunción diastólica y sistólica y la disfunción endotelial. Sin embargo, como el daño cardiaco también se correlaciona con la duración de la enfermedad, el efecto del tratamiento depende del momento del diagnóstico, el éxito de la cirugía y el momento en el que se indica el tratamiento ${ }^{30}$. Colao, et al. describieron el efecto de los LRS (ligandos del receptor de somatostatina) sobre el índice de masa ventricular izquierda, concluyendo que la cardiomiopatía acromegálica disminuye significativamente en la mayoría de los pacientes jóvenes y con menos tiempo de evolución, al mismo tiempo que mejora la fracción de eyección del ventrículo izquierdo ${ }^{34}$. En un metaanálisis de 18 estudios realizado en el 2007 se demostró que el uso de LRS se asocia a efectos positivos significativos en parámetros morfológicos y hemodinámicos funcionales tales como la frecuencia cardiaca, la PA, la masa del ventrículo izquierdo, el índice de masa del ventrículo izquierdo, el grosor del septum interventricular y de la pared posterior ventricular, el diámetro diastólico final, la relación del flujo mitral temprano y tardío, la fracción de eyección y la duración del ejercicio $^{40}$. Los resultados de los estudios coinciden en que el control de los niveles de GH/IGF-1, sin importar el tipo de tratamiento, mejora en general la ECV del paciente con acromegalia ${ }^{31}$. También disminuyen los focos ectópicos ventriculares, disminuye el intervalo QT y el grosor de la íntima-media de las arterias; 
además, al mejorar la apnea obstructiva del sueño, el perfil de lípidos y las alteraciones en la tolerancia a la glucosa, también disminuye el riesgo $\mathrm{CV}^{28}$.

A pesar de la efectividad de los tratamientos dirigidos a reducir los niveles de GH/IGF-1, es importante trabajar en forma paralela en las modificaciones del estilo de vida (que incluyan la suspensión del tabaquismo), el tratamiento farmacológico de la $\mathrm{HA}$, la insuficiencia cardiaca y las arritmias y el control de las alteraciones metabólicas.

\section{APNEA DEL SUEÑO Y NEUMOPATÍA EN} ACROMEGALIA

El crecimiento de los tejidos del tracto respiratorio superior en los pacientes con acromegalia se relaciona con un aumento en la incidencia del síndrome de apnea obstructiva del sueño (SAOS), el cual se caracteriza por un cese o disminución del flujo de aire durante el sueño, produciéndose alteración del sueño, ronquidos, inquietud, entre otros síntomas. Estos afectan la calidad de vida y, en casos graves, se asocian a un incremento en la morbilidad y mortalidad $\mathrm{CV}^{41}$. La prevalencia informada de SAOS en acromegalia es del 44 al $87.5 \%$ en casos de enfermedad activa y del 35 al $58 \%$ en enfermedad controlada, observándose una asociación entre los síntomas y los niveles de IGF-142. Esta enfermedad desencadena repercusiones en el sistema CV, siendo un factor de riesgo independiente de isquemia, arritmia y otros trastornos CV. Todo paciente con acromegalia debe ser evaluado para detectar SAOS con una historia clínica completa, un cuestionario de valoración del sueño y la implementación de escalas como Epworth o STOP-BANG; se debe confirmar la sospecha mediante la polisomnografía ${ }^{43}$.

\section{COMPLICACIONES METABÓLICAS EN ACROMEGALIA}

La prevalencia de diabetes en acromegalia es muy variable, con rangos que van del 11 al 53\%, con un promedio del $30 \%$ y por lo tanto mayor de lo observado en la población general ${ }^{31}$. Algunos factores que contribuyen a esta diferencia en la prevalencia son la etnicidad y los métodos para diagnosticar diabetes.

La GH interviene en el metabolismo de la glucosa al regular de manera directa tanto la secreción como la acción de la insulina. Los niveles elevados de GH e IGF-1 ocasionan resistencia a la insulina, por lo que aumentan el riesgo de diabetes y de $\mathrm{ECV}^{31}$. Se ha observado que algunos factores asociados al desarrollo de diabetes en pacientes con acromegalia son mayor edad, sexo femenino, duración de la acromegalia, historia familiar de diabetes y niveles elevados de GH e IGF- ${ }^{44}$.

El control bioquímico de la acromegalia después del tratamiento puede mejorar las alteraciones en el metabolismo de los carbohidratos; sin embargo, esto no significa necesariamente que en todos los casos haya remisión, pudiendo observarse incluso el desarrollo de novo de diabetes después del tratamiento ${ }^{45}$. El tratamiento integral de los pacientes es fundamental, enfocándose no solo en el control de la GH y el IGF-1, sino también en el tratamiento específico de cada comorbilidad. El control de la diabetes debe ser estricto, sin que existan recomendaciones particulares respecto al uso de algún antidiabético en específico.

\section{ALTERACIONES ÓSEAS Y NEUROMUSCULARES EN ACROMEGALIA}

\section{Fragilidad ósea y fracturas}

La acromegalia se asocia con fragilidad ósea e incremento en el riesgo de fracturas; ello ocurre a pesar de los conocidos efectos anabólicos en el crecimiento longitudinal y en el modelamiento óseo y del hecho de que los pacientes con acromegalia tienen huesos de mayor tamaño que los individuos sanos.

Un metaanálisis que evaluó el metabolismo óseo en acromegalia encontró que las tasas de formación y de resorción están elevadas en pacientes con 
acromegalia con respecto a los controles. A pesar de esos hallazgos, los pacientes con acromegalia tuvieron mayor razón de riesgo de fracturas vertebrales, siendo los principales marcadores de riesgo el género masculino, el estado de hipogonadismo y la actividad de la enfermedad ${ }^{42}$; los dos últimos factores mencionados parecen actuar de manera independiente y ello se ha demostrado en varios estudios. En general, los estudios muestran que el incremento en la resorción es mayor que el incremento en la formación ósea, lo que resulta en pérdida ósea.

El sistema GH/IGF-1 puede estimular la actividad de la 1-alfa-hidroxilasa, lo cual teóricamente llevaría a un efecto benéfico óseo; sin embargo, algunos estudios han encontrado deficiencia de vitamina $D$ (evaluada por la medición de 25-hidroxivitamina D). También se ha encontrado elevación de la proteína fijadora de vitamina D en acromegalia, lo cual causaría una disminución en la biodisponibilidad periférica. Bioquímicamente es frecuente la hiperfosfatemia leve debida a que el sistema GH/IGF-1 aumenta la reabsorción tubular de fósforo y al incremento en la absorción intestinal por calcitriol; también es frecuente la hipercalciuria, explicada por el incremento en la absorción intestinal de calcio por el aumento en las concentraciones de calcitriol y al ya mencionado incremento en la resorción ósea inducido por el exceso de GH.

El exceso de GH aumenta la formación de osteofitos y la hipertrofia facetaria, lo cual puede llevar a una sobreestimación de la densidad ósea en la columna lumbar. El exceso de GH y de IGF-1 tiene un efecto negativo en la microarquitectura trabecular, mientras que hay un efecto benéfico en la densidad cortical como resultado de una acción positiva de GH en la osificación perióstica ${ }^{47}$.

Un estudio que usó morfometría vertebral y radiología encontró fracturas vertebrales en la mitad de las mujeres posmenopáusicas con acromegalia, a pesar de que se observó osteoporosis por densitometría en un porcentaje mucho menor; las fracturas eran múltiples en más de dos terceras partes de las mujeres con fracturas ${ }^{48}$. Otro estudio encontró fracturas vertebrales en 23 de 40 hombres con acromegalia ${ }^{49}$. Las fracturas vertebrales parecen ser levemente más frecuentes en hombres que en mujeres y el estado gonadal es un factor de riesgo importante ${ }^{50}$. Es de interés hacer notar que las fracturas vertebrales parecen ser más frecuentes en la columna torácica.

Se recomienda la medición de la masa ósea mediante absorciometría de rayos $\mathrm{X}$ de doble energía en todos los pacientes con acromegalia y la realización de radiografías de columna dorsal y lumbosacra en posiciones anteroposterior y lateral para la detección de fracturas vertebrales. Aunque no hay datos para decidir la frecuencia de dichos estudios, es razonable la evaluación anual en ambos casos.

Los efectos del tratamiento sobre los desenlaces óseos son complejos. El remodelamiento óseo disminuye y los efectos en la densitometría ósea son variables. El control bioquímico de la enfermedad, logrado con cualquier tipo de tratamiento, se ha asociado a menor incidencia de fracturas, pero la presencia de hipogonadismo no tratado y de diabetes mellitus parecen contrarrestar el efecto benéfico del control de la enfermedad.

\section{Enfermedad articular}

La artropatía por acromegalia es una manifestación inicial de la enfermedad en el 50 al $70 \%$ de los casos y la prevalencia de osteoartrosis en la enfermedad es de al menos el $75 \%$; una serie informó un $92 \%$ de afección en columna cervical ${ }^{51}$. Se considera que la artropatía es de 4 a 12 veces más frecuente que en la población general. No existe un sistema para categorizar la severidad de la artropatía específicamente diseñado para acromegalia. La ausencia de escalas aplicables específicamente para acromegalia es una limitante también en la evaluación de la mejoría sintomática y funcional: se usan escalas de osteoartrosis primaria ante la ausencia de una escala diseñada especialmente para acromegalia; estos últimos tipos de escalas permiten al menos evaluar algunos aspectos de la calidad de vida y su mejoría con el tratamiento, lo cual es importante en acromegalia, pues los datos articulares pueden afectar significativamente la calidad de vida de los pacientes.

En fases iniciales, el exceso de GH estimula la producción local de IGF-1 en el cartílago; esta producción se 
suma al exceso de IGF-1 circulante, lo que resulta en replicación e hiperfunción de los condrocitos articulares y aumento de la síntesis de la matriz. El cartílago empieza a engrosarse, causando ensanchamiento del espacio articular, alteración de la geometría normal de la articulación e hipermovilidad articular. La hipertrofia sinovial exacerba la alteración en la carga mecánica en la articulación; hasta esta etapa, el control de la secreción de GH e IGF-1 parece revertir la artropatía. Algunos estudios han sugerido que la IGFBP3 puede aumentar la acción del IGF-1, mientras que la IGFBP4 parece inhibirla. Cuando la enfermedad progresa aparecen fisuras en la superficie del cartílago y existe proliferación de tejido fibrocartilaginoso de regeneración en mayor proporción que en la osteoartrosis primaria, probablemente por efecto del exceso de GH. El tejido fibrocartilaginoso se calcifica y lleva a la formación de osteofitos; también puede calcificarse la cápsula articular y, ocasionalmente, aparecer condrocalcinosis. En casos más avanzados las fisuras pueden extenderse al hueso subcondral y causar ulceración del cartílago articular; se pueden formar quistes subcondrales y existe aumento en la resorción del tejido óseo subyacente. Finalmente, el cartílago articular se adelgaza y el grosor del espacio articular disminuye, características observadas en la osteoartrosis; en esta etapa el control de la secreción de GH y de IGF-1 no mejora la artropatía. El sobrecrecimiento óseo y el edema de tejidos blandos pueden causar atrapamiento nervioso; algunos cambios articulares podrían ser irreversibles.

Se recomienda realizar radiografías de las articulaciones afectadas; en algunas ocasiones puede requerirse una resonancia magnética (RM). Un estudio informó que 6 de 40 (15\%) pacientes evaluados tenían datos radiológicos de hiperostosis esquelética idiopática difusa (DISH), la cual es una enfermedad que se manifiesta por una tendencia a la osificación de ligamentos, tendones, periostio y cápsulas articulares y que afecta tanto a la columna vertebral como a estructuras extraespinales ${ }^{52}$. Un estudio previo había informado una prevalencia de DISH del $47 \%$ en 30 pacientes con acromegalia ${ }^{53}$; en ese mismo estudio se había informado una prevalencia del $67 \%$ de entesopatía (mineralización de inserciones ligamentosas) marcada en talones y una prevalencia del $87 \%$ de hiperostosis frontal interna. La extensión y severidad de tales cambios estuvo relacionada con la duración de la acromegalia. Se propuso entonces que un factor común, específicamente la hiperinsulinemia, podría ser responsable de los cambios hiperostóticos observados en la DISH y en la acromegalia. De particular interés es el prognatismo, hallazgo típico en acromegalia, que puede causar maloclusión dental y síndrome de la articulación temporomandibular en hasta una tercera parte de los pacientes.

Algunos estudios han mostrado reversibilidad parcial del engrosamiento del espacio articular con LRS. En la mayoría de los casos el fenotipo radiográfico persiste después del control de la enfermedad, pero algunos estudios sugieren mejoría en los signos y síntomas de la artropatía acromegálica con el tratamiento quirúrgico o farmacológico; ello parece más probable en las etapas tempranas, cuando existe engrosamiento articular y ensanchamiento del espacio articular. La mejoría parece ser más frecuente en los síntomas que en los datos radiológicos, al menos en observaciones hechas con tratamiento farmacológico; puede decirse que en periodos variables de observación, la mejoría sintomática y funcional al menos no parece acompañarse de un deterioro adicional al presente inicialmente (en cuanto a lesiones cartilaginosas y óseas) cuando se controla la acromegalia con LRS. La mejoría sintomática parece estar más bien relacionada con la disminución del volumen de tejidos blandos que ocurre con el tratamiento ${ }^{54}$. En el 10 al $15 \%$ de los casos hay disminución del espacio articular; en esos casos aparecen los síntomas articulares más severos y probablemente se trata del grupo de pacientes que han tenido enfermedad de larga evolución con periodos prolongados de enfermedad activa. Un estudio mostró más del $70 \%$ de este desenlace a pesar de enfermedad controlada a largo plazo ${ }^{55}$. El tratamiento general de apoyo, como paracetamol, antiinflamatorios no esteroideos y el uso juicioso de inyecciones locales de esteroides pueden ser considerados, así como la cirugía de reemplazo cuando se considere clínicamente necesario. Se requieren estudios que evalúen si el tratamiento estricto de la actividad de la acromegalia afecta al desenlace de la artropatía acromegálica.

Algunos estudios han sugerido que hay relación entre la severidad bioquímica de la acromegalia y 
Tabla 4. Tamizaje de cáncer en pacientes con acromegalia

\begin{tabular}{llllll}
\hline Cáncer & SIR & IC 95\% & Tamizaje & Frecuencia & Método \\
\hline Colon & 2.6 & $1.7-4.0$ & Al diagnóstico & Cada 5 años & Colonoscopia \\
\hline Tiroides & 9.2 & $4.2-20$ & Al diagnóstico & Cada año & Ultrasonido \\
\hline Próstata & 1.5 & $1.0-2.3$ & Al diagnóstico & Cada año & Antígeno prostático específico \\
\hline Mama & 1.6 & $1.1-2.3$ & Al diagnóstico & Cada año & Ultrasonido o mastografía \\
\hline
\end{tabular}

SIR: razón de incidencia estandarizada (standardized incidence ratio); IC 95\%: intervalo de confianza del 95\%.

el tiempo de enfermedad no controlada con la severidad de la artropatía; otros estudios no han encontrado tal relación. Se puede concluir que el pronóstico de la artropatía depende del éxito del tratamiento instituido y de la etapa de la enfermedad: los cambios de engrosamiento articular pueden ser revertidos en etapas tempranas con tratamiento exitoso, mientras que las deformidades óseas y las osteoartrosis establecidas son características tardías de la enfermedad que no revierten.

\section{CÁNCER Y ACROMEGALIA}

La frecuencia de cáncer está ligeramente incrementada en acromegalia en comparación con los casos esperados en población general. Los tipos de cáncer más frecuentes son el cáncer colorrectal, tiroideo y en menor frecuencia de próstata y mama. De 10 series informadas, 8 demuestran incremento consistente en el riesgo ${ }^{56,57}$. En pacientes con acromegalia, la tasa de incidencia estandarizada (SIR) de cáncer en hombres es de 1.5 (1.3-1.7) y en mujeres de $1.9(1.4-2.5)^{58}$. Al analizar la SIR por tipo de cáncer se encuentra significativamente incrementada para cáncer colorrectal (2.6 [1.7-4.0]) y tiroideo (9.2 [4.220]) y con menor frecuencia el gástrico (2.0 [1-4$2.9])$, mama (1.6 [1.1-2.3]) y próstata $(1.5[1.0-2.3])^{58}$.

\section{Cáncer de colon}

El tamizaje para cáncer de colon se recomienda con colonoscopia al diagnóstico de acromegalia, independientemente de la edad del paciente. En caso de no encontrarse alteración, el tamizaje se realizará siguiendo las guías para población general. Los hallazgos anormales deberán estudiarse y tratarse de acuerdo con las recomendaciones específicas del padecimiento. Los resultados anormales esperados son con mayor frecuencia de pólipos, mayor longitud y pliegues colónicos, además de mayor riesgo de adenocarcinoma. La biopsia y estudio histopatológico, por lo tanto, son necesarios ${ }^{59-61}$.

\section{Cáncer de tiroides}

El bocio multinodular y el cáncer diferenciado papilar tiroideo son más frecuentes en pacientes con acromegalia. El 25\% de los nódulos presentarán crecimiento. Sin embargo, la indicación de aspirado con aguja fina sigue las mismas recomendaciones para pacientes con nódulo tiroideo independientemente del diagnóstico de acromegalia. Por ello, los nódulos tiroideos con datos sugestivos de malignidad por el estudio convencional (que es el ultrasonido) deberán ser evaluados con aspiración y seguir las normas actuales para su estudio y tratamiento ${ }^{62,63}$.

\section{Otros tipos de cáncer}

Los hombres con acromegalia tienen mayor frecuencia de cambios estructurales en la próstata, como son mayor volumen y mayor clínica obstructiva ${ }^{62}$. Estos cambios no tienen relación con la edad y sí con la duración y actividad de la acromegalia. Se recomienda tamizaje inicial y en caso de ser negativo, vigilancia, como indican las guías para la población general. En el caso de las mujeres, el ultrasonido de mama o mastografía debe realizarse al diagnóstico de acromegalia. En caso de encontrar anormalidades se seguirá la conducta habitual en población general. No se recomienda tamizaje para 
otro tipo de neoplasias, sin embargo, la clínica deberá de normar la conducta y el paciente con acromegalia deberá estudiarse a fondo cuando se sospeche malignidad (Tabla 4).

\section{TRATAMIENTO QUIRÚRGICO}

\section{Indicaciones}

La cirugía hipofisaria transesfenoidal realizada por un neurocirujano experimentado es el tratamiento primario de elección de los adenomas productores de GH. Una cirugía exitosa disminuye inmediatamente los niveles de GH y se obtendrá tejido tumoral para una adecuada caracterización histopatológica. El abordaje transcraneal se reserva en tumores grandes e invasores, con fines descompresivos o franca invasión al seno cavernoso ${ }^{64,65}$.

La reintervención quirúrgica se recomienda para eliminación de remanente y no con objetivos de curación. Se prefiere en pacientes con enfermedad persistente severa cuyo tumor original era un macroadenoma no invasivo. Se aconseja que existan las siguientes condiciones: disponibilidad de un cirujano experto, comorbilidades cardiopulmonares controladas, cantidad suficiente de tumor accesible dentro o por encima de la silla turca ${ }^{66}$.

\section{Control tumoral y bioquímico}

El objetivo quirúrgico es la resección máxima de la lesión tumoral para aliviar el efecto de masa, disminuir la hipersomatotropinemia a niveles normales y la preservación de la función hormonal de las líneas hipofisiarias. Los marcadores para remisión quirúrgica incluyen la RM hipofisaria, que debe realizarse hasta después de las 12 semanas del procedimiento quirúrgico y si existían defectos del campo visual se puede emplear campimetría computarizada bilateral hasta al año de seguimiento, ya que algunos pacientes pueden mejorar en este periodo ${ }^{67,68}$.

Se recomienda medir niveles de GH e IGF-1 después de 12 semanas de la cirugía; un nivel de $\mathrm{GH}<1 \mu \mathrm{g} / \mathrm{l}$ asociado a un nivel de IGF- $1<1.2$ veces por arriba del LSN para la edad representan los objetivos terapéuticos y se correlacionan con el control de la enfermedad. Se sugiere también solicitar niveles de supresión de GH por glucosa; cuando el nadir de $\mathrm{GH}$ es $<1 \mu \mathrm{g} / \mathrm{l}$, los resultados a largo plazo son mejores ${ }^{10}$.

\section{LIGANDOS DEL RECEPTOR DE SOMATOSTATINA COMO TRATAMIENTO COMPLEMENTARIO A LA CIRUGÍA}

La cirugía hipofisaria es el tratamiento de elección en acromegalia, pero la remisión de la enfermedad puede variar en macroadenomas invasores o no invasores; en los invasores la remisión puede ser menor del $10 \%{ }^{69}$. En estos casos de persistencia de actividad de la enfermedad, el tratamiento multimodal se torna importante y otras opciones como la desmasificación quirúrgica combinada con el tratamiento con LRS o la utilización prequirúrgica de estos pueden mejorar la respuesta al fármaco y los desenlaces de tratamiento.

El efecto de la desmasificación quirúrgica y la respuesta farmacológica a LRS se evaluó en un estudio, buscando la respuesta a octreótida de depósito antes y después de la resección parcial del tumor en 11 pacientes, que no pudieron normalizar sus niveles de IGF-1 después del tratamiento primario con octreótida durante una media de 16 meses; se encontró que al reiniciar la terapia con la LRS, el $80 \%$ de estos sujetos alcanzaron un IGF-1 normal ${ }^{70}$.

El uso de LRS en pacientes con acromegalia programados para cirugía puede mejorar el control de comorbilidades metabólicas preoperatorias y reducir el riesgo de complicaciones cardiopulmonares perioperatorias $^{71}$. El efecto del uso preoperatorio de LRS sobre la tasa de éxito quirúrgico es motivo de controversia. Un metaanálisis reciente concluyó que el tratamiento preoperatorio con octreótida o lanreótida puede mejorar el resultado quirúrgico, en términos de alcanzar los criterios de remisión bioquímica, aunque la evidencia disponible muestra resultados contradictorios ${ }^{72}$. El uso de LRS preoperatorios puede estar justificado cuando la espera de tiempo quirúrgico es prolongada, situación común en nuestro medio. 


\section{Ligandos del receptor de somatostatina}

La somatostatina es la hormona encargada de inhibir la secreción de GH; actúa al unirse a su receptor, del cual existen 5 tipos (SSTR1-5). Los adenomas productores de $\mathrm{GH}$ expresan principalmente SSTR2 (95\%) y SSTR5 (85\%), seguidos del SSTR1 y SSTR3 en un $40 \%{ }^{73}$. La octreótida fue aprobada por la FDA (Food and Drug Administration) en 1988 para tratamiento de acromegalia ${ }^{74}$. Actualmente contamos con octreótida LAR y lanreótida autogel, LRS de primera generación de liberación prolongada que actúan principalmente al unirse al SSTR2. La pasireótida LAR es un ligando de segunda generación multirreceptor, que se une con mayor afinidad al receptor SSTR5, seguido del SSTR2 y SSTR3 $^{73}$.

\section{Indicaciones}

Su principal indicación es como terapia adyuvante en enfermedad persistente después del tratamiento quirúrgico. Es la primera línea de tratamiento en pacientes que no son candidatos a cirugía (en casos en los que no se observa tumor, este sea inaccesible para resección o exista un alto riesgo quirúrgico) y en aquellos pacientes que no desean tratamiento quirúrgico. Como se mencionó previamente, podría considerase en pacientes con macroadenomas antes de la cirugía para mejorar comorbilidades, aunque su papel es controvertido. Tienen un papel importante en tumores grandes o invasivos, en los que se sabe que la intervención quirúrgica no controlará la enfermedad; así, su uso como tratamiento primario puede conseguir a largo plazo disminuir el tamaño del tumor, de tal manera que la cirugía tenga más posibilidades de lograr el control de la enfermedad ${ }^{75}$.

\section{CONTROL BIOQUÍMICO}

Se considera control bioquímico una $\mathrm{GH}$ aleatoria $<1 \mu \mathrm{g} / \mathrm{l}$, con IGF-1 normal para edad. En la literatura la definición de control bioquímico varía dependiendo de si los LRS se utilizan como terapia de primera línea o como terapia adyuvante (después de cirugía o RT), así como el criterio de GH e IGF-1 utilizado para definir control.

- Ligandos de primera generación: la octreótida LAR a dosis de $20 \mathrm{mg}$ mensual intramuscular y la lanreótida autogel administrada 90 mg subcutánea mensual, tienen una respuesta bioquímica similar que oscila entre el $17-55 \%{ }^{75}$. Existen informes de pacientes parcialmente respondedores (disminución > 50\% GH/IGF-1), que son casos en los que el incrementar la dosis o disminuir el intervalo en la aplicación podría ser una medida eficaz para lograr control bioquímico. Se inicia tratamiento mensual y se solicitan control de GH basal e IGF-1 a las 12 semanas; la curva con supresión de GH no se considera necesaria. En caso de usar octreótida LAR se puede titular la dosis de 10 a 40 mg mensuales; en el caso de lanreótida autogel, se pueden administrar de 60 a 120 mg mensuales $^{75}$.

- Ligandos de segunda generación: la pasireótida LAR se considera segunda línea de tratamiento médico, aunque su efecto es superior al de la octreótida ${ }^{76}$. La hiperglucemia es un efecto secundario bastante común, por lo que se reserva para pacientes que muestran resistencia a ligandos de primera generación. Además, su limitada disponibilidad y su alto costo son factores que lo hacen ser una opción poco práctica ${ }^{75}$.

- Resistencia bioquímica: se define como una disminución $<50 \%$ de GH/IGF-1 y ocurre en el 20 al $25 \%$ con los ligandos de primera generación. Esta resistencia se ha asociado a un patrón por IHQ escasamente granulado y correlaciona con hiperintensidad en $\mathrm{T} 2$ en la $\mathrm{RM}^{77}$. Estos tumores usualmente presentan menor expresión de SSTR2. Los pacientes suelen ser hombres jóvenes y con niveles de $\mathrm{GH}$ pretratamiento muy elevados ${ }^{78}$.

Al usar LRS existe reducción tumoral por su efecto antiproliferativo ${ }^{73,75}$. Esta usualmente se correlaciona con la disminución de $\mathrm{GH}$ y generalmente ocurre en los primeros tres meses de tratamiento ${ }^{75}$. Se considera que hay resistencia tumoral si durante el tratamiento hay incremento de volumen tumoral o cuando la reducción es menor al 20\% ${ }^{78}$. 


\section{Efectos adversos}

- Los efectos secundarios más comunes son gastrointestinales: dolor abdominal, flatulencia y diarrea. Generalmente son transitorios ${ }^{10}$.

- Irritación y dolor en el sitio de aplicación ${ }^{10}$.

- Hiperglucemia: puede presentarse con cualquier LRS, pero su prevalencia es mucho mayor con la pasireótida, ocurriendo hasta en el $70 \%{ }^{73}$. Los niveles de hemoglobina glucosilada y el antecedente de hiperglucemia son los principales predictores para presentar este efecto adverso, por lo que se recomienda medir la glucosa semanalmente durante los primeros tres meses del tratamiento ${ }^{75}$.

- Colelitiasis: únicamente se recomienda realizar ultrasonido en caso de un cuadro clínico característico, por lo que no es necesario solicitarlo al inicio del tratamiento ${ }^{75}$.

- Algunos efectos poco comunes son la caída de cabello e incluso la alopecia ${ }^{75}$.

\section{AGONISTAS DOPAMINÉRGICOS}

Muchos datos apoyan el uso de agonistas del receptor de dopamina en el tratamiento de la acromegalia debido a la evidencia de presencia de receptores D2 en los tumores de somatotropos, así como heterodímeros de estos con receptores SSTR5, cuyo complejo se une a una proteína Gi. Sugerimos el uso de una dosis de 1 a $3 \mathrm{mg}$ a la semana. Se ha evidenciado que el tratamiento de tumores de somatotropos con agonistas de dopamina disminuye la secreción de $\mathrm{GH}$ hasta un $25 \%$ o más ${ }^{79}$. Los agonistas de dopamina se han usado en el tratamiento de la acromegalia desde 1934. Inicialmente se utilizaba bromocriptina, pero se requerían grandes dosis y solo se lograba supresión de $\mathrm{GH}$ a $<5 \mathrm{mg} / \mathrm{l}$ en el $20 \%$ de los pacientes y se normalizaba el IGF-1 en el $10 \%^{80}$.

En 1998 se hizo el primer estudio multicéntrico que evaluó el uso de cabergolina en 64 pacientes con acromegalia no seleccionados, obteniéndose una reducción de IGF-1 a menos de $300 \mu \mathrm{g} / \mathrm{l}$ en el $39 \%$ de los casos y de $\mathrm{GH}$ a menos de $2 \mu \mathrm{g} / \mathrm{l}$ en el $46 \%$, con lo cual se evidenció que la cabergolina tenía mejor efectividad que la bromocriptina en el tratamiento de acromegalia. Esto es debido a que la cabergolina tiene mayor afinidad por el receptor D2 y una vida media más larga ${ }^{92}$.

El uso de cabergolina puede ser más eficaz en pacientes seleccionados, sobre todo en aquellos tumores cosecretores de PRL. No obstante, en este tipo de pacientes tampoco ha sido consistente una respuesta exitosa. En pacientes más típicos con acromegalia, se encontró en un estudio realizado en el 2004 que solo el $21 \%$ de un grupo de 14 pacientes postoperados tratados con cabergolina, hasta 18 meses, tuvo una normalización persistente de IGF-182.

Un metaanálisis en el 2011 valoró la eficacia del uso de cabergolina como tratamiento en acromegalia, considerando a pacientes que fueron tratados únicamente con este fármaco y a pacientes que fueron tratados en combinación con LRS. Se observó que el control del IGF-1 en los pacientes con acromegalia se obtuvo en un tercio de los pacientes que fueron tratados con cabergolina y en más de la mitad en los que recibieron tratamiento combinado con LRS. La eficacia de la cabergolina dependió del nivel basal de IGF-1; sin embargo, se observó que pacientes con IGF-1 muy elevado lograban una normalización de los valores ${ }^{83}$.

En un ensayo prospectivo con 52 pacientes que tenían 12 meses de tratamiento con LRS se agregó al tratamiento cabergolina y el $40.4 \%$ de los pacientes normalizó el IGF-1 en seis meses al agregar 1.0-3.0 $\mathrm{mg} /$ semana de cabergolina ${ }^{84}$.

\section{RADIOTERAPIA}

La RT actúa mediante radiación ionizante produciendo daño al DNA y con ello apoptosis del tejido tumoral. Ha sido utilizada por más de 100 años en el tratamiento de acromegalia ${ }^{74,85}$. Es una terapia efectiva para el control tumoral y bioquímico ${ }^{86}$. Con el avance en el tratamiento médico ha quedo como terapia de tercera línea; sin embargo, en los últimos 
años la RT ha tenido un importante avance con el advenimiento de nuevas técnicas que permiten mayor precisión para localizar el tumor, minimizando la radiación al resto del parénquima cerebral ${ }^{87}$.

\section{Indicaciones}

Las indicaciones actuales de RT son la presencia de tumor residual o recurrente (después de una cirugía), la resistencia al tratamiento médico, cuando este no sea tolerado o no esté disponible ${ }^{10}$. Podría ser la primera línea de tratamiento en pacientes que no son candidatos a cirugía por sus comorbilidades (evitando así el alto costo del tratamiento médico de por vida) y posiblemente en aquellos tumores que por patología demuestran datos de agresividad ${ }^{88}$.

\section{Tipos de radioterapia}

Actualmente existen dos tipos de RT: convencional y estereotáctica. Esta última puede ser fraccionada o radiocirugía ${ }^{80}$. La RT convencional (RTC) es la terapia más antigua; se administran 40-54 Gy divididos en 20 sesiones. Es la terapia con mayores índices de remisión tumoral, pero mayores efectos secundarios a largo plazo y mayor tiempo de latencia para control bioquímico (de 5 a 15 años) ${ }^{80}$.

En la RT estereotáctica (RTE) se administran dosis mayores de radiación al tejido blanco, con mayor precisión para localizar el tumor ${ }^{80}$, permitiendo menores efectos secundarios y menor tiempo de latencia para control bioquímico ( 2 años) ${ }^{89}$. Esta es la terapia de elección a menos que el tumor esté muy cercano al quiasma óptico o exista demasiado tumor residual, con más de $3 \mathrm{~cm}^{23,85}$.

La radiocirugía ( $\mathrm{Rqx}$ ) puede ser administrada como gamma knife, cyberknife o acelerador lineal. Usualmente se administra en una sola dosis o como una modalidad hipofraccionada dividida en un máximo de cinco dosis. Se requiere que el nervio óptico se encuentre a una distancia de 2 a $3 \mathrm{~mm}$.

La RT fraccionada se administra con un acelerador lineal, con la misma dosis que la RTC, fraccionada en 22-30 sesiones, con la ventaja de tener mayor exactitud (de 1 a $2 \mathrm{~mm}$ ) que la convencional ${ }^{85}$.

\section{Control tumoral y control bioquímico}

El control tumoral y bioquímico varía según el tipo de RT utilizada y si esta se utiliza como terapia inicial o terapia adyuvante. El rango de control bioquímico es muy amplio en la literatura debido a la variación de criterios utilizados para determinar normalización de GH/IGF-1.

- Control tumoral: RTC 80-100\%, Rqx 93-100\%.

- Control bioquímico: RTC $60-80 \%$, Rqx 44-52\% a 5 años, $47-82 \%$ a 10 años $^{85}$.

\section{Efectos secundarios}

- Tempranos: náuseas, fatiga, caída de cabello, disminución en gusto y olfato ${ }^{90}$.

- Tardíos: hipopituitarismo (30-80\% RTC, 0-66\% RTE), radionecrosis (0-10\% RTC), tumores secundarios (2\% 10 a 20 años RTC, 0-1\% RTE), EVC (4-22\% 5 a 20 años RTC), daño a estructuras adyacentes (neuropatía óptica 0-5\% RTC, 0-1\% Rqx), disfunción neurocognitiva e incremento de mortalidad (1.6-2.2; usualmente debido a EVC). Este incremento de mortalidad no ha sido demostrado con las nuevas modalidades de $\mathrm{RT}^{75,85}$. Se considera que el riesgo de hipopituitarismo es menor con $\mathrm{Rqx}^{89}$; sin embargo, el seguimiento a largo plazo es limitado y existe demasiada heterogeneidad en los estudios que dificulta realizar esta comparación. Se requieren estudios con mayor tiempo de seguimiento que evalúen los efectos a largo plazo incluyendo mortalidad y EVC, para comprobar si las posibles ventajas mencionadas de la Rqx se mantienen a largo plazo ${ }^{85,90}$.

\section{Ventajas}

La RT es una terapia rentable a largo plazo ${ }^{91,93}$. A diferencia a lo observado con el uso de terapia médica, la granulación no es un factor pronóstico de respuesta a $\mathrm{RT}^{85,87}$.

\section{Desventajas}

Una de las principales desventajas es el tiempo de latencia para control bioquímico, que va de 2 a 
Tratamiento inicial del paciente con acromegalia

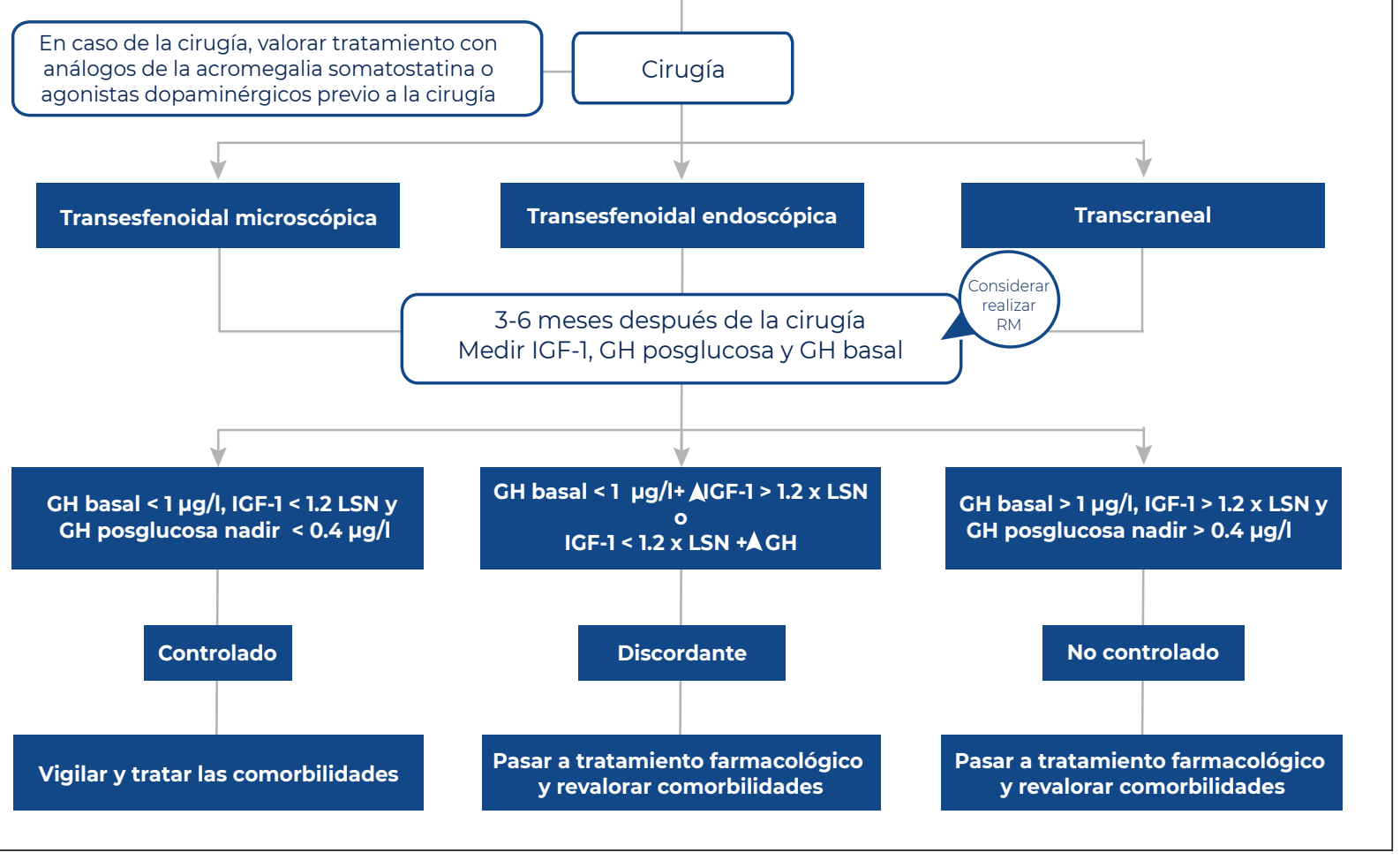

Figura 2. Tratamiento inicial del paciente con acromegalia. IGF-1: factor de crecimiento similar a la insulina tipo 1; GH: hormona de crecimiento; RM: resonancia magnética; LSN: límite superior del rango de normalidad.

15 años, por lo cual deberá otorgarse tratamiento médico en espera de respuesta al tratamiento ${ }^{85}$. Existe controversia respecto a si durante la RT se debe suspender el tratamiento médico, pues podría disminuir la efectividad de esta ${ }^{85,87}$. Debido a que la literatura es controvertida hasta el momento, no está indicado suspender el tratamiento médico $^{10}$.

La RT continúa siendo un tratamiento efectivo para el control tumoral y bioquímico en acromegalia. Es necesaria la valoración por un radiooncólogo para indicar la modalidad y la dosis de RT considerando el tamaño tumoral, su localización y los marcadores de $\mathrm{IHQ}^{88}$. El tratamiento basado en las características del paciente, su evolución y su respuesta a tratamiento permite mejores desenlaces clínicos, reduciendo gastos económicos.

En las figuras 2 y 3 se resumen las recomendaciones del consenso para el tratamiento de la acromegalia.

\section{CONCLUSIONES}

La evidencia sobre la historia natural de la acromegalia, sus complicaciones y la respuesta a los tratamientos disponibles, se encuentra en constante actualización. Es fundamental continuar el desarrollo de estudios específicos en nuestro país para aumentar la comprensión del comportamiento de la enfermedad en nuestra población. Su diagnóstico oportuno requiere un alto índice de sospecha y los pacientes deben ser referidos de forma temprana a un tercer nivel de atención, en donde el tratamiento debe llevarse a cabo por un equipo multidisciplinario con experiencia en la enfermedad. Aunque este manejo debe adaptarse a las posibilidades sociales y económicas de cada región, se debe brindar a los pacientes las modalidades terapéuticas disponibles, según sus indicaciones específicas, de forma oportuna, con el objetivo de evitar 


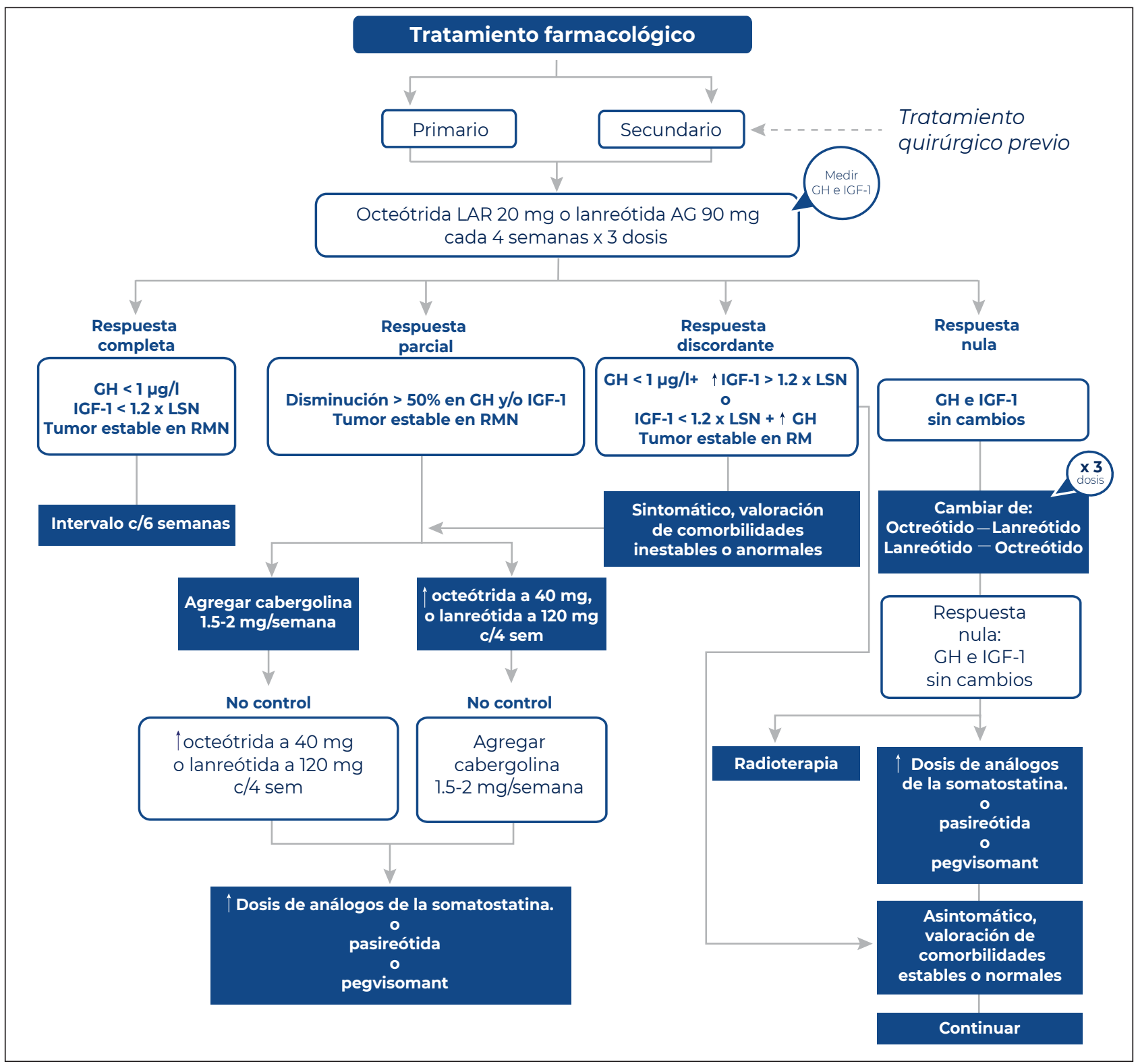

Figura 3. Tratamiento farmacológico. IGF-1: factor de crecimiento similar a la insulina tipo 1; GH: hormona de crecimiento; RM: resonancia magnética; LSN: límite superior del rango de normalidad.

la progresión de las comorbilidades asociadas a la acromegalia.

\section{CONFLICTO DE INTERESES}

Los autores que declaran conflicto por intereses son: Ana Laura Espinosa de los Monteros, Daniel Cuevas, Ernesto Sosa y Moisés Mercado, debido a que han sido conferencistas y consultantes para Novartis Oncología México y para IPSEN México.

\section{FINANCIAMIENTO}

La presente investigación no ha recibido algún apoyo económico específico proveniente de agencias del sector público, del sector comercial o de entidades sin ánimo de lucro. 
RESPONSABILIDADES ÉTICAS

Protección de personas y animales. Los autores declaran que para esta investigación no se ha realizado experimentos en seres humanos ni animales.

Confidencialidad de lo datos. Los autores declaran que en este artículo no aparecen datos de pacientes.

Derecho a la privacidad y consentimiento informado. Los autores declaran que en este artículo no aparecen datos de pacientes.

\section{BIBLIOGRAFÍA}

1. Arellano $S$, Aguilar $P$, Domínguez B, Espinosa de los Monteros AL, González Virla B, Sosa E, et al. Segundo Consenso Nacional de Acromegalia: Recomendaciones para su diagnostico, tratamiento y seguimiento. Rev Endocrinol Nutr. 2007;15(3 Supl 1):S7-S17.

2. Consenso Nacional de Acromegalia: Guía para su diagnóstico, tratamiento y seguimiento. Rev Endocrinol Nutr. 2004;12(3 Supl 2):S63-S72.

3. Pokrajac A, Wark G, Ellis AR, Wear J, Wieringa GE, Trainer PJ. Variation in $\mathrm{GH}$ and IGF-I assays limits the applicability of international consensus criteria to local practice. Clin Endocrinol (Oxf). 2007;67(1):65-70.

4. Bidlingmaier M, Friedrich N, Emeny RT, Spranger J, Wolthers OD, Roswall J, et al. Reference intervals for insulin-like growth factor-1 (IGF-1) from birth to senescence: results from a multicenter study using a new automated chemiluminescence IGF-I immunoassay conforming to recent international recommendations. J Clin Endocrinol Metab. 2014;99(5):1712-21.

5. Espinosa de los Monteros AL, Sosa-Eroza E, Gonzalez B, Mendoza V, Mercado M. Prevalence, clinical and biochemical spectrum, and treatment outcome of acromegaly with normal basal GH at diagnosis. J Clin Endocrinol Metab. 2018;103(10):3919-24.

6. Clemmons DR. IGF-I assays: current assay methodologies and their limitations. Pituitary. 2007;10(2):121-8.

7. Clemmons DR. Consensus statement on the standardization and evaluation of growth hormone and insulin-like growth factor assays. Clin Chem. 2011:57(4):555-9.

8. Sata A, Ho KKY. Growth hormone measurements in the diagnosis and monitoring. Pituitary. 2007;10:165-72.

9. Mercado M, Abreu C, Vergara-López A, González-Virla B, Espinosa-delos-Monteros AL, Sosa-Eroza, et al. Surgical and pharmacological outcomes in acromegaly: Real-life data from the Mexican Acromegaly Registry. J Clin Endocrinol Metab. 2020;105(12):dgaa664.

10. Katznelson L, Laws ER Jr, Melmed S, Molitch ME, Murad MH, Utz A, et al. Endocrine Society. Acromegaly: an endocrine society clinical practice guideline. J Clin Endocrinol Metab. 2014;99(11):3933-51.

11. Schilbach K, Strasburger CJ, Bidlingmaier M. Biochemical investigations in diagnosis and follow up of acromegaly. Pituitary. 2017;20(1):33-45.

12. Bristow AF, Jespersen AM. The Second International Standard for somatropin (recombinant DNA-derived human growth hormone): preparation and calibration in an international collaborative study. Biologicals. 2001;29(2):97-106.

13. Ribeiro de Oliveira Longo Schweizer J, Ribeiro-Oliveira A Jr, Bidlingmaier $M$. Growth hormone: isoforms, clinical aspects and assays interference. Clin Diabetes Endocrinol. 2018;28;4:18.

14. Syro LV, Rotondo F, Serna CA, Ortiz LD, Kovacs K. Pathology of GH-producing pituitary adenomas and GH cell hyperplasia of the pituitary. Pituitary. 2017;20(1):84-92.

15. Lopes MB. Growth hormone-secreting adenomas: pathology and cell biology. Neurosurg Focus. 2010;29(4):E2.

16. Melmed S. Pituitary medicine from discovery to patient-focused outcomes. J Clin Endocrinol Metab. 2016;101(3):769-77.
17. Raverot G, Jouanneau E, Trouillas J. Management of endocrine disease: clinicopathological classification and molecular markers of pituitary tumours for personalized therapeutic strategies. Eur J Endocrinol. 2014;170(4):R121-32

18. Mete O, Lopes MB. Overview of the $2017 \mathrm{WHO}$ classification of pituitary tumors. Endocr Pathol. 2017;28(3):228-43.

19. Cuevas-Ramos D, Carmichael JD, Cooper O, Bonert VS, Gertych A, Mamelak AN, et al. A structural and functional acromegaly classification. J Clin Endocrinol Metab. 2015;100(1):122-31.

20. Ramos Leví AM, Marazuela M. Cardiovascular comorbidities in acromegaly: an update on their diagnosis and management. Endocrine. 2017;55(2):346-59.

21. Holdaway IM. Tretment of acromegaly. Horm Res. 2004;62 Suppl 3:79-92.

22. Ritvoten E, Löyttyniemi E, Jaatinen P, Ebeling T, Moilnen L, Nuutila P, et al. Mortality in acromegaly: a 20-years follow-up study. Endocr Relat Cancer. 2016;23(6):469-80.

23. Colao A, Grasso LFS, Giustina A, Melmed S, Chanson P, Pereira AM, et al. Acromegaly. Nat Rev Dis Primers. 2019;5(1):20.

24. Portocarrero-Ortiz LA, Vergara-Lopez A, Vidrio-Velazquez M, Uribe-Diaz AM, García-Dominguez A, Reza-Albarrán AA, et al. Mexican Acromegaly Registry Group. The Mexican Acromegaly Registry: Clinical and biochemical characteristics at diagnosis and therapeutic outcomes. J Clin Endocrinol Metab. 2016;101(11):3997-4004.

25. Bondanelli M, Ambrosio MR, degli Uberti EC. Pathogenesis and prevalence of hypertension in acromegaly. Pituitary. 200;4(4):239-49.

26. Costenaro F, Martin A, Horn RF, Czepielewski MA, Rodrigues TC. Role of ambulatory blood pressure monitoring in patients with acromegaly. J Hypertens. 2016; 34:1357-63.

27. Schutte AE, Volpe M, Tocci G, Conti E. Revisiting the relationship between blood pressure and insulin-like growth factor-1. Hypertension. 2014;63(5):1070-7.

28. Ramos-Leví AM, Marazuela M. Bringing cardiovascular comorbidities in acromegaly to an update. How should we diagnose and manage them? Front Endocrinol (Lausanne). 2019;10:120.

29. Kamenicky P, Viengchareun S, Blanchard A, Meduri G, Zizzari P, ImbertTeboul $M$, et al. Epithelial sodium channel is a key mediator of growth hormone-induced sodium retention in acromegaly. Endocrinology. 2008;149(7):3294-305.

30. Pivonello R, Auriemma RS, Grasso LF, Pivonello C, Simeoli C, Patalano R, et al. Complications of acromegaly: cardiovascular, respiratory and metabolic comorbidities. Pituitary. 2017;20(1):46-62.

31. Gadelha MR, Kasuki L, Lim DST, Fleseriu M. Systemic complications of acromegaly and the impact of the current treatment landscape: An Update. End Rev. 2019;40:268-332.

32. Popielarz-Grygalewicz A, Gasior JS, Konwicka A, Grygalewicz P, Stelmachowska-Banás $M$, Zgliczynski W, et al. Heart in acromegaly: the echocardiographic characteristics of patients diagnosed with acromegaly in various stages of the disease. Int J Endocrinol. 2018;2018:6935054.

33. Dal J, Feldt-Rasmussen U, Andersen M, Kristensen LO, Laurberg P, Pedersen $\mathrm{L}$, et al. Acromegaly incidence, prevalence, complications and long-term prognosis: a nationwide cohort study. Eur J Endocrinol. 2016;175(3):181-90.

34. Colao A, Marzullo P, Cuocolo A, Spinelli L, Pivonello R, Bonaduce D, et al. Reversal of acromegalic cardiomyopathy in young but not in middle aged patients after 12 months of treatment with the depot long-acting somatostin analogue octreotide. Clin Endocrinol. 2003;58:169-76.

35. Pereira AM, van Thiel SW, Lindner JR, Roelfsema F, van der Wall EE, Morreau $\mathrm{H}$, et al. Increased prevalence of regurgitant valvular heart disease in acromegaly. J Clin Endocrinol Metab. 2004;89:71-5.

36. Casini AF, Neto LV, Fontes R, França RF, Xavier SS, Gadelha MR. Aortic root ectasia in patients with acromegaly: experience at a single center. Clin Endocrinol (Oxf). 2011;75(4):495-500.

37. Kırıs A, Erem C, Turan OE, Civan N, Kırış G, Nuhoğlu I, et al. Left ventricular synchronicity is impaired in patients with active acromegaly. Endocr. 2013;44:200-6.

38. Maione M, Chanson PH. National acromegaly registries. Best Pract Res Clin Endocrinol Metab. 2019;6:101264.

39. Schöfl C, Petroff D, Tönjes A, Grussendorf M, Droste M, Stalla G, et al. Incidence of myocardial infarction and stroke in acromegaly patients: results from the German Acromegaly Registry. Pituitary. 2017;20:635-42.

40. Maison P, Tropeano Al, Macquin-Mavier I, Giustina A, Chanson P. Impact of somatostatin analogs on the heart in acromegaly: a metaanalysis. J Clin Endocrinol Metab. 2007;92(5):1743-7.

41. Wolters TLC, Roerink SHPP, Drenthen LCA, van Haren-Willems JHGM, Wagenmakers MAEM, Smit JWA, et al. The course of obstructive sleep apnea syndrome in patients with acromegaly during treatment. J Clin Endocrinol Metab. 2020;105(1):dgz050.

42. Vouzouneraki K, Franklin KA, Forsgren M, Wärn M, Persson JT, Wik H, et al. Temporal relationship of sleep apnea and acromegaly: a nationwide study. Endocrine. 2018;62(2):456-63. 
43. Attal P, Chanson P. Endocrine aspects of obstructive sleep apnea. J Clin Endocrinol Metab. 2010;95(2):483-95.

44. Espinosa de los Monteros AL, González B, Vargas G, Sosa E, Mercado M. Clinical and biochemical characteristics of acromegalic patients with different abnormalities in glucose metabolism. Pituitary. 2011;14:231-5.

45. González B, Vargas G, Espinosa de los Monteros AL, Mendoza V, Mercado M. Persistence of diabetes and hypertension after multimodal treatment of acromegaly. J Clin Endocrinol Metab. 2018;103:2369-75.

46. Mazziotti G, Biagioli E, Maffezzoni F, Spinello M, Serra V, Maroldi R, et al. Bone turnover, bone mineral density, and fracture risk in acromegaly: a meta-analysis. J Clin Endocrinol Metab. 2015;100(2):384-94.

47. Giustina A, Mazziotti G, Canalis E. Growth hormone, insulin-like growth factors, and the skeleton. Endocr Rev. 2008;29(5):535-59.

48. Bonadonna S, Mazziotti G, Nuzzo M, Bianchi A, Fusco A, De Marinis L, et al. Increased prevalence of radiological spinal deformities in active acromegaly: a cross-sectional study in postmenopausal women. J Bone Miner Res. 2005;20(10):1837-44.

49. Mazziotti G, Bianchi A, Bonadonna S, Cimino V, Patelli I, Fusco A, et al. Prevalence of vertebral fractures in men with acromegaly. J Clin Endocrinol Metab. 2008;93(12):4649-55.

50. Mazziotti G, Frara S, Giustina A. Pituitary diseases and bone. Endocr Rev. 2018;39(4):440-88.

51. Wassenaar MJ, Biermasz NR, van Duinen N, van der Klaauw, Pereira AM, Roelfsema $F$, et al. High prevalence of arthropathy, according to the definitions of radiological and clinical osteoarthritis, in patients with long-term cure of acromegaly: a case-control study. Eur J Endocrinol. 2009:160(3):357-65

52. Örük $G$, Tarhan $F$, Argın M, Özmen $M$. Is every joint symptom related to acromegaly? Endocrine. 2013;43(2):404-11.

53. Littlejohn GO, Hall S, Brand CA, Davidson A. New bone formation in acromegaly: pathogenic implication for diffuse idiopathic skeletal hyperostosis. Clin Exp Rheumatol. 1986;4(2):99-104.

54. Layton MW, Fudman EJ, Barkan A, Braunstein EM, Fox IH. Acromegalic arthropathy: characteristics and response to therapy. Arthritis Rheum. 1988;31:1022-7.

55. Claessen KM, Ramautar SR, Pereira AM, Smit JW, Roelfsema F, Romijn JA, et al. Progression of acromegalic arthropathy despite long-term biochemical control: a prospective, radiological study. Eur J Endocrinol. 2012;167:235-44

56. Dworakowska D, Gueorguiev M, Kelly P, Monson JP, Besser GM, Chew SL, et al. Repeated colonoscopic screening of patients with acromegaly: 15year experience identifies those at risk of new colonic neoplasia and allows for effective screening guidelines. Eur J Endocrinol. 2010;163(1):21-8.

57. Mercado M, Gonzalez B, Vargas G, Ramirez C, Espinosa de los Monteros AL, Sosa E, et al. Successful mortality reduction and control of comorbidities in patients with acromegaly followed at a highly specialized multidisciplinary clinic. J Clin Endocrinol Metab. 2014;99(12):4438-46.

58. Dal J, Leisner MZ, Hermansen K, Farkas DK, Bengtsen M, Kistorp C, et al. Cancer incidence in patients with acromegaly: A cohort study and metaanalysis of the literature. J Clin Endocrinol Metab. 2018;103(6):2182-8.

59. Rokkas T, Pistiolas D, Sechopoulos P, Margantinis G, Koukoulis G. Risk of colorectal neoplasm in patients with acromegaly: a meta-analysis. World J Gastroenterol. 2008;14(22):3484-9.

60. Jenkins PJ, Fairclough PD; British Society for Gastroenterology; Association of Coloproctology for Great Britain and Ireland. Screening guidelines for colorectal cancer and polyps in patients with acromegaly. Gut. 2002;51 Suppl 5(Suppl 5):V13-4

61. Levin B, Lieberman DA, McFarland B, Andrews KS, Brooks D, Bond J, et al. Screening and surveillance for the early detection of colorectal cancer and adenomatous polyps, 2008: a joint guideline from the American Cancer Society, the US Multi-Society Task Force on Colorectal Cancer, and the American College of Radiology. Gastroenterology. 2008;134(5):1570-95

62. Dogansen SC, Salmaslioglu A, Yalin GY, Tanrikulu S, Yarman S. Evaluation of the natural course of thyroid nodules in patients with acromegaly. Pituitary. 2019;22(1):29-36.

63. Wolinski K, Czarnywojtek A, Ruchala M. Risk of thyroid nodular disease and thyroid cancer in patients with acromegaly-meta-analysis and systematic review. PLoS One. 2014;9(2):e88787.

64. Abosch A, Tyrrell JB, Lamborn KR, Hannegan LT, Applebury CB, Wilson CB. Transsphenoidal microsurgery for growth hormone-secreting pituitary adenomas: initial outcome and long-term results. J Clin Endocrinol Metab. 1998:83(10):3411-8.

65. Espinosa de los Monteros AL, Sosa E, Cheng S, Ochoa R, Sandoval C, Guinto $\mathrm{G}$, et al. Biochemical evaluation of disease activity after pituitary surgery in acromegaly: a critical analysis of patients who spontaneously change disease status. Clin Endocrinol (Oxf). 2006;64(3):245-9.
66. Espinosa de los Monteros AL, González B, Vargas G, Sosa E, Guinto G, Mercado M. Surgical reintervention in acromegaly: is it still worth trying? Endocr Pract. 2009;15(5):431-7.

67. Dina TS, Feaster SH, Laws ER Jr, Davis DO. MR of the pituitary gland postsurgery: serial MR studies following transsphenoidal resection. AJNR Am J Neuroradiol. 1993;14(3):763-9.

68. Krieger MD, Couldwell WT, Weiss MH. Assessment of long-term remission of acromegaly following surgery. J Neurosurg. 2003;98(4):719-24

69. Nomikos P, Buchfelder M, Fahlbusch R. The outcome of surgery in 668 patients with acromegaly using current criteria of biochemical 'cure'. Eur J Endocrinol. 2005;152(3):379-87.

70. Jallad RS, Musolino NR, Kodaira S, Cescato VA, Bronstein MD. Does partial surgical tumour removal influence the response to octreotide-LAR in acromegalic patients previously resistant to the somatostatin analogue? Clin Endocrinol (Oxf). 2007;67(2):310-5.

71. Jacob JJ, Bevan JS. Should all patients with acromegaly receive somatostatin analogue therapy before surgery and, if so, for how long? Clin Endocrinol (Oxf). 2014;81(6):812-7.

72. Pita-Gutierrez F, Pertega-Diaz S, Pita-Fernandez S, Pena L, Lugo G, Sangiao-Alvarellos $S$, et al. Place of preoperative treatment of acromegaly with somatostatin analog on surgical outcome: a systematic review and meta-analysis. PLoS One. 2013;8(4):e61523.

73. Cuevas-Ramos D, Fleseriu M. Pasireotide: a novel treatment for patients with acromegaly. Drug Des Devel Ther. 2016;10:227-39.

74. de Herder WW. The history of acromegaly. Neuroendocrinology. 2016;103(1):7-17

75. Giustina A, Chanson P, Kleinberg D, Bronstein MD, Clemmons DR, Klibanski A, et al. Acromegaly Consensus Group. Expert consensus document: A consensus on the medical treatment of acromegaly. Nat Rev Endocrinol. 2014;10(4):243-8.

76. Colao A, Bronstein MD, Freda P, Gu F, Shen CC, Gadelha M, et al. Pasireotide C2305 Study Group. Pasireotide versus octreotide in acromegaly: a head-to-head superiority study. J Clin Endocrinol Metab. 2014;99(3):791-9.

77. Bollerslev J, Heck A, Olarescu NC. Management of endocrine disease: Individualised management of acromegaly. Eur J Endocrinol. 2019;181(2):R57-R71.

78. Kasuki L, Wildemberg LE, Gadelha MR. Management of endocrine disease: Personalized medicine in the treatment of acromegaly. Eur J Endocrinol. 2018:178(3):R89-R100.

79. Cooper O, Greenman Y. Dopamine agonists for pituitary adenomas. Front Endocrinol (Lausanne). 2018;9:469.

80. Jaffe CA, Barkan AL. Treatment of acromegaly with dopamine agonists. Endocrinol Metab Clin North Am. 1992;21:713-35.

81. Abs R, Verhelst J, Maiter D, van Acker K, Nobels F, Coolens JL, et al. Cabergoline in the treatment of acromegaly: a study in 64 patients. J Clin Endocrinol Metab. 1998;83(2):374-8.

82. Freda P, Reyes C, Nuruzzaman A, Sundeen R, Khandji A, Kalmon D. Cabergoline therapy of growth hormone \& growth hormone/prolactin secreting pituitary tumors. Pituitary. 2004;7:21-30.

83. Sandret L, Maison P, Chanson P. Place of cabergoline in acromegaly: a meta-analysis. J Clin Endocrinol Metab. 2011;96(5):1327-35.

84. Vilar L, Azevedo MF, Naves LA, Casulari LA, Albuquerque JL, Montenegro $\mathrm{RM}$, et al. Role of the addition of cabergoline to the management of acromegalic patients resistant to longterm treatment with octreotide LAR. Pituitary. 2011;14(2):148-56.

85. Gheorghiu ML. Updates in outcomes of stereotactic radiation therapy in acromegaly. Pituitary. 2017;20(1):154-68.

86. Minniti G, Scaringi C, Enrici RM. Radiation techniques for acromegaly. Radiat Oncol. 2011:6:167.

87. Gheorghiu ML, Fleseriu M. Stereotactic radiation therapy in pituitary adenomas, is it better than conventional radiation therapy? Acta Endocrinol (Buchar). 2017;13(4):476-90.

88. Raverot G, Burman P, McCormack A, Heaney A, Petersenn S, Popovic V, et al. European Society of Endocrinology. European Society of Endocrinology Clinical Practice Guidelines for the management of aggressive pituitary tumours and carcinomas. Eur J Endocrinol. 2018;178(1): G1-G24.

89. Mohammed N, Ding D, Hung YC, Xu Z, Lee CC, Kano H, et al. Primary versus postoperative stereotactic radiosurgery for acromegaly: a multicenter matched cohort study. J Neurosurg. 2019:1-10.

90. Petersenn S. Management of aggressive pituitary tumors - A 2019 update. Horm Metab Res. 2019;51(12):755-64.

91. Elbaum M, Mizera L, Bolanowski M. The real costs of acromegaly: analysis of different therapies. Endokrynol Pol. 2019;70(1): 74-85.

92. González B, Vargas G, Espinosa-de-los-Monteros AL, Sosa E, Mercado M. Efficacy and safety of radiotherapy in acromegaly. Arch Med Res. 2011;42(1):48-52. 